\title{
Reliability Analysis of Primary and Purification Pumps in RSG-GAS Using Monte Carlo Simulation Approach
}

\author{
Entin Hartini ${ }^{1}$, Hery Adrial ${ }^{1}$, Santosa Pujiarta ${ }^{2}$ \\ ${ }^{1}$ Center for Nuclear Reactor Technology and Safety (PTKRN Batan),Kawasan Puspiptek, Tangerang Selatan, 15310, Indonesia \\ ${ }^{2}$ Center For Multipurpose Reactor, Kawasan Puspiptek, Tangerang Selatan, 15310, Indonesia
}

\section{ARTICLE INFO}

Article history:

Received: 30 January 2019

Received in revised form: 18 February 2019

Accepted: 19 February 2019

Keywords:

Reliability

Monte Carlo

Component damage

RSG-GAS

\begin{abstract}
A B S T R A C T
Reliability and maintenance play an important role in ensuring successful operation of a system. Reliability analysis is often used to determine the probability whether or not a system is functioning. However, limited available data and information are causing uncertainties and inaccuracies on component parameters. The purpose of this study is to conduct component/system reliability analysis using Monte Carlo simulation-based method. This method enables us to estimate the reliability of components/systems including parameter uncertainty and imprecision. It is also useful to predict and evaluate maintenance decisions related to reliability. Monte Carlo method employs random number generation based on the probability of the distribution of processed data, of which then validated with real available data to ensure the simulation condition is relatively similar to real-life condition. The data used in this research is failure data on RSGGAS components/systems for core configuration number of 81 to 95 , accumulated from year 2013 to 2018 . The results show that reliability values of components JE01/AP01-02 on TTF 233.619 is 0.579 while for components KBE01/AP-01-02 in TTF 185.38 is 0.368 . The component reliability value is $60 \%$, which implies that maintenance may be performed after 225 days and 100 days for componentsJE01/AP01-02 and KBE01/AP01-02, respectively.
\end{abstract}

(C) 2019 Tri Dasa Mega. All rights reserved.

\section{INTRODUCTION}

Reliability and maintenance play an important role in order to ensure successful operation of a nuclear reactor. Maintenance and its policy are necessary to achieve effective system operation with minimum cost. Preventive maintenance is a crucial factor to maintain component utilization while ensuring its failure level remains low. However, limited available data can make it troublesome to characterize component failure timing. This is due to component/system reliability

\footnotetext{
*Corresponding author. Tel./Fax.:021 756 0912/756 0913

E-mail: entin@batan.go.id DOI: $10.17146 / \mathrm{tdm} .2019 .21 .1 .5311$
}

as well as performance is directly influenced by uncertainty [1-5].

Reliability analysis hasbeen extensively used to minimize the failure rate. Some examples are Andriulo et al. who proposed effectiveness of maintenance approaches for high reliability organizations, as well as mentioned by Florian et al., Vishnu et al. and Taheri et al. [6-8].

Reliability analysis is performed by implementing Monte Carlo simulation. The basic of Monte Carlo method is utilization of random number generation during the simulation process. This random number is created based on the probability of the distribution of data. Then, it is validated with real data to verify the result [9-12]. 
The focus of this research is the reliability analysis of primary pumps and purification in RSGGAS using the Monte Carlo Simulation approach. Simulation approaches for maintenace and reliability analysis have been carried out by many researchers. Propose optimal care strategies using discrete-event Monte Carlo simulations [13]. Make a definition of maintenance policy in the power system using Sequential Monte Carlo [14]. Apply the Multilevel Monte Carlo method to reliability theory [15]. Proposes a probabilistic Monte Carlo method for modeling and predicting the age of electronic components [16]. Popose Markov Chain Monte Carlo simulation method for structural reliability analysis [17]. Perform computer simulation models for estimation of complex system reliability [18]. Perform analysis of the system reliability of Monte Carlo with human operators [19].

The purpose of this research is to analyze component reliability by employing Monte Carlobased simulation. MCS is used in evaluating reliability in the failure of the RSG-GAS component due to the degradation of the components due to aging. This proposed method is able to estimate the realistic component reliability, including parameter uncertainty and imprecision. Monte Carlo method can also be used to predict and evaluate the maintenance decision related to reliability.

Methodology used in this research is identifying the problem, determining time-to-failure (TTF) of component and data distribution conformity test. Those steps are then followed by parameter estimation using Maximum Likelihood method and MCS based on parametric value estimation in accordance to component failure data. Lastly, the reliability value is calculated based on real data and MCS result. The data used is RSGGAS component failure time for core configuration number of 81-95, accumulated during year 2013$2018[20]$.

\section{THEORY}

\section{Monte Carlo Simulation}

Monte Carlo Simulation (MCS) is originated from sampling statistics, employing random number as input and probability as a means to solve real-world problem by simulation. MCS has simple program structure and flexible simulation process. Therefore, MCS is selected as simulation method to determine the degradation process of a component/system.
The basic principle of the MCS is shown in the following equation.

$$
Y=f\left(x_{1}, x_{2}, \ldots, x_{n}\right)
$$

Where $x_{1}, x_{2}, \cdots x_{n}$ are random variables and $y$ is dependent variable.

The equation is considerably complicated when applied to most of the practical problem, while on the other hand, it is quite difficult to calculate $y$-probability distribution and its mathematical characteristics using analytical method. However, MCS is able to calculate the sampled values, both directly or indirectly, of each set variables $\left(x_{1 i}, x_{2 i}, \cdots x_{n i}\right)$ with a random number generator, then calculate the value $y_{i}$ according to equation (1). One set of data sampling $y$ is obtained by repeating the sampling process. The estimation of the function of $y$ probability distribution and its mathematical characteristic is able to approach the actual condition by increasing simulation time. The accuracy of $y$ may be provided with standard deviation from estimated value.

\section{Basic Principle of MCS}

The basic principle of MCS is defining the probability density function (PDF) with probability in every possible result, sums up the PDF as a cumulative probability function and adjusts the maximum value to 1 in aprocess also known as normalization. The PDF is a probability characteristic of the total probability for all events. It also establishes the connection between the random number sampling and the real problem simulation.

There are 3 steps involved when performing MCS. The first step, generating samples from the input variable $\mathrm{x}$ with the appropriate data distribution.Second, experimenting with numerical problems leads to performance analysis. Last, performing statistical analysis on output result[9].

\section{Sampling on input random variables}

The purpose of sampling on the input random variables $X_{i}=\left(x_{1}, x_{2}, . ., x_{n}\right)$ is to generate samples that represent distributions of the input variable from their $c d f \mathrm{~s} F_{x i}(x i)(\mathrm{i}=1,2, \ldots n)$. The samples of the random variables will then be used as inputs to the simulation experiments. Two steps are involved for this purpose: Step 1 - generate distributed data random variables and; Step 2 - transforming the values of the variable of distributed data obtained from Step 1 to the values of random variables that follow the given distributions $F_{x i}\left(x_{i}\right)(\mathrm{i}=1,2, \ldots n)$ 
The task is to transform the samples of distributed variable $\mathbf{z}=\left(z_{1}, z_{2}, . ., z_{N}\right)$ where $N$ is the number of samples generated from Step 1, into values of random variable $X i$ that follows a given distribution $F_{x i}\left(x_{i}\right)$. There are several methods to perform such transformation. The simple and direct method is the inverse transformation method. By this method, the random variable is given by.

$$
x_{i}=F_{x i}^{-1}\left(z_{i}\right), \quad(\mathrm{i}=1,2, \ldots N)
$$

where $F_{x i}^{-1}$ is the inverse of the $c d f$ of the random variable $X$.

If $X$ is normally distributed with $N\left(\mu_{x}, \sigma_{x}\right)$, since

$$
z=F_{x}=\varphi\left(\frac{x-\mu_{x}}{\sigma_{x}}\right)
$$

then

$$
x_{i}=F_{x i}^{-1}\left(z_{i}\right), \quad(\mathrm{i}=1,2, \ldots N)
$$

And if $X$ is exponentially distributed with $E\left(x_{i}\right)=(1 / \lambda)$ since

$$
F_{\mathrm{x}}=\mathrm{R}-1=1-\exp (-\lambda \mathrm{x})
$$

then

$$
x_{i}=\frac{-1}{\lambda} \ln \left(1-\mathrm{R}_{\mathrm{i}}\right)
$$

\section{Numerical Experimentation}

Suppose that $N$ samples of each random variable are generated, then all the samples of random variables constitute $N$ sets of inputs $x_{\mathrm{i}}=\left(x_{i 1}, x_{i 2}, \ldots, x_{1 n}\right), i=1,2, \ldots, N$ to the model $Y=g(x)$. Solving the problem $N$ times deterministically yields $N$ sample points of the output $Y$.

$$
y_{\mathrm{i}}=g(x), i=1,2, \ldots, N
$$

\section{Probabilistic information of output variables}

After $N$ samples of output $Y$ have been obtained, statistical analysis can be carried out to estimate the characteristics of the output $Y$, such as the mean, variance, reliability, the probability of failure, PDF and CDF. The associated equations are given below of the mean

$$
\bar{y}=\frac{1}{N} \sum_{\mathrm{i}=1}^{\mathrm{N}} \mathrm{yi}
$$

and the variance

$$
\sigma_{y}^{2}=\frac{1}{N-1} \sum_{\mathrm{i}=1}^{\mathrm{N}}(\mathrm{yi}-\overline{\mathrm{y}})
$$

\section{Random Number Generation}

Random number generation for TTF data from component/system is the first step to perform MCS. Random number that ought to be generated is based on probability distribution from preliminary data of component TTF of coolant system. Random number generation of TTF from RSG-GAS component/system is performed to obtain a number with similar distribution with TTF data population. The first step to generate random number is determining probability distribution from data variable TTF, based on probability distribution from preliminary data of TTF.

\section{Parameter Estimation}

Prior to generating samples, it is necessary to determine index of fit using Anderson-Darling test, approached by test statistic as shown [12].

$$
A^{2}=-N-\frac{1}{N} \sum_{1=1}^{N}[2 i-1]\left[\ln \left(F\left(t_{i}\right)\right)+\ln \left(1-\left(F\left(t_{N+1+i}\right)\right]\right.\right.
$$

The next step is estimating parameter based on PDF using data obtained from index of fit. Parameter estimation using Maximum Likelihood for density function of normal distribution $(\mu, \sigma)$ is dan $\mu=\vec{x}$ dan $\mathrm{s}=\sigma$, while exponential distribution parameter is $\lambda=1 / E\left(x_{i}\right)$

\section{Component/System Reliability}

Reliability represents the probability of a component/system of being success up to time $t$, in other word, the failure happens after $t$. It is stated with following equation.

$$
R(t)=P(T>t), t \geq 0
$$

where $T$ is a random variable which expressesTTF with failure time distribution is stated as

$$
F(t)=P(T<t), t \leq 0
$$

thus

$$
R(t)=1-F(t)
$$

and

$$
d R(t) / d t=-d F(t) / d t=-f(t)
$$

where $f(t)$ is a function of density.

Reliability function of data with normal distribution is stated by the following,

$$
R(t)=1-\Phi\left[\frac{t-\mu}{\sigma}\right]
$$


while data reliability function with exponential distribution is stated as follows,

$$
R(t)=\exp [-(\lambda t)]
$$

\section{METHODOLOGY}

The method employed to analyze the reliability of primary and purification pump is based on real TTF data and MCS. TTF of components with high downtime and frequency of failure. The data used is RSG-GAS component failure time for core configuration number of 8195, year 2013-2018.

The sequence of methodology is explained as follows:

1. Determine the appropriate data distribution from failure data by conducting a compatibility test between component failure data distribution and parameter estimation using the Maximum Likelihood method.

2. Perform MCS based on estimation of parametric values according to PDF component failure data.

3. Calculate the value of reliability based on real data and MCS

4. Analysis of results.

\section{RESULTS AND DISCUSSION}

Base on the component/system maintenance data, the most frequently damaged and most downtime component in coolant system is the primary pump JE01/AP-01-02 and component in primary purification system is primary purification pump is KBE01/AP-01-02. Component JE01/AP01-02 encountered 7 times of failure and 1704 hours of downtime, whilst component KBE01/AP01-02 encountered 11 times of failure and124 hours of downtime. Reliability analysis using MCS approach and real data is performed to both components. The data evaluated is TTF. The TTF data of both components are shown in the Table 1 and Table 2.

Table 1. TTF Data on Primary Pump JE-01 (AP01-02)

\begin{tabular}{ccc}
\multicolumn{3}{c}{ JE-01 (AP01-02) } \\
$\begin{array}{c}\text { Core } \\
\text { Number }\end{array}$ & Failure time & $\begin{array}{l}\text { TTF } \\
\text { (days) }\end{array}$ \\
\hline 83 & $02 / 06 / 2013$ & 0 \\
85 & $07 / 03 / 2014$ & 278 \\
85 & $01 / 04 / 2014$ & 25 \\
87 & $18 / 02 / 2015$ & 323 \\
88 & $04 / 08 / 2015$ & 167 \\
91 & $07 / 05 / 2016$ & 277 \\
91 & $19 / 09 / 2016$ & 135 \\
\hline
\end{tabular}

Table 2. TTF Data on Primary Purification Pump KBE01/AP-01-02

\begin{tabular}{ccc}
\hline $\begin{array}{c}\text { Core } \\
\text { Number }\end{array}$ & Failure time & $\begin{array}{c}\text { TTF } \\
\text { (days) }\end{array}$ \\
\hline 82 & $14 / 04 / 2013$ & 0 \\
83 & $08 / 08 / 2013$ & 116 \\
83 & $13 / 08 / 2013$ & 5 \\
85 & $16 / 01 / 2014$ & 156 \\
85 & $06 / 02 / 2014$ & 21 \\
85 & $25 / 04 / 2014$ & 70 \\
86 & $21 / 07 / 2014$ & 87 \\
87 & $03 / 02 / 2015$ & 197 \\
90 & $01 / 04 / 2016$ & 423 \\
92 & $22 / 03 / 2017$ & 355 \\
94 & $12 / 11 / 2017$ & 235 \\
\hline
\end{tabular}

Distribution conformity test using Anderson Darling (AD) method is shown in Figure $\mathbf{1}$ and Figure 2. Its testing criterion is hypothesis acceptance on significancy level $\alpha$ if value $p \geq$ value $\alpha$. Using AD table, the testing criterion is hypothesis acceptance if $\mathrm{AD}_{\text {(calculation) }}<\mathrm{AD}_{\text {(table) }}$.

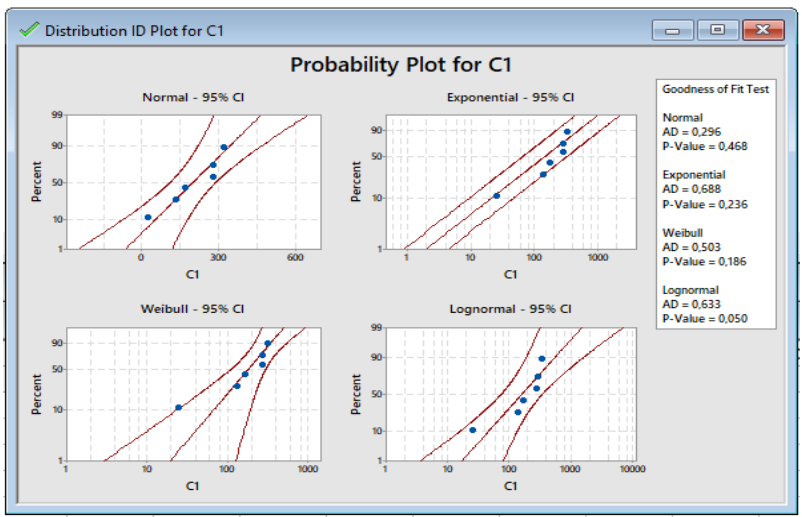

Fig. 1. Distribution test result of component JE01 (AP01-02)

From Figure 1, it is understood that value $\mathrm{p}>$ $\alpha>0.05$. Thus, it is obtained $p_{\text {value }}=0.468$ and $\mathrm{AD}_{\text {(calculation) }}=0.296<\mathrm{AD}_{\text {(table) }}=1.013$. Therefore, it can be concluded that the component JE01 (AP0102) has normal distribution. This means the hypothesis is accepted. 


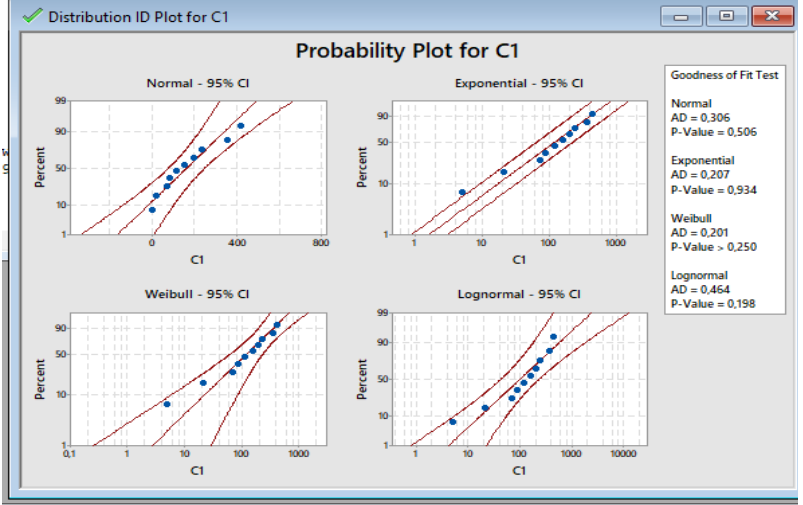

Fig. 2. Distribution test result of component KBE01/AP-01-02

Meanwhile, from Figure $2 b$, it is obtained that the $\mathrm{p}_{\text {value }}=0.934$ and $\mathrm{AD}_{\text {(calculation) }}=0.207<\mathrm{AD}_{\text {(table) }}$ $=1.321$. This means that, contrary to the other one, the component KBE01/AP-01-02 has exponential distribution.

The parametric estimation result of failure data employing MLE method for normally distributed component JE01 (AP01-02) are $\mu=200.833$ and $\sigma=112.31$, which is exponentially distributed. KBE01/AP-01-02 are $\lambda=0.00601$ and mean $=166.5$. These results are used for MCS.

\section{Random Number Generation of Monte Carlo Simulation}

Generation of random number for TTF data of the component of JE01 (AP01-02) and KBE01/AP01-02 is the first stage to run a Monte Carlo simulation. The random number to be generated is based on the probability distribution. The generation of random TTF components of JE01 (AP01-02) andKBE01/AP-01-02 are intended to produce figures that have equal distribution with data population of TTF of the actual component of JE01 (AP01-02) and KBE01/AP-01-02. The first step in generating random number is to determine the probability distribution of the data variables of TTF for each component of the system.

Next, determine random number for TTF data of which interval of random number has been predetermined on the previous stage. The random number results using MCS for components JE01/ AP01-02 are normally distributed and KBE01 / AP01-02 are exponentially distributed with the number of samples $\mathrm{N}=20$, average $=152.091$ and $\lambda=$ 0.00658 . Table 3 and Table 4 elaborate the results.
Table 3. Random Number Result of Component JE01 (AP01-02)

\begin{tabular}{cccc}
\hline $\begin{array}{c}\text { No } \\
\text { Sampel }\end{array}$ & $\begin{array}{c}\text { Random } \\
\text { Number }\end{array}$ & $\begin{array}{c}\text { No } \\
\text { Sampel }\end{array}$ & $\begin{array}{c}\text { Random } \\
\text { Number }\end{array}$ \\
\hline 1 & 340.86440 & 11 & 168.70502 \\
2 & 226.76610 & 12 & 157.58264 \\
3 & 85.653836 & 13 & 271.31870 \\
4 & 124.13181 & 14 & 94.539670 \\
5 & 343.35735 & 15 & 148.43560 \\
6 & 145.30792 & 16 & 59.511860 \\
7 & 73.021180 & 17 & 202.37314 \\
8 & 323.61218 & 18 & 20.102950 \\
9 & 165.31851 & 19 & 56.991870 \\
10 & 356.96394 & 20 & 15.345860 \\
\hline
\end{tabular}

Table 4. Random Number Result of Component KBE01/AP-01-02

\begin{tabular}{cccc}
\hline $\begin{array}{c}\text { No } \\
\text { Sampel }\end{array}$ & $\begin{array}{c}\text { Random } \\
\text { Number }\end{array}$ & $\begin{array}{c}\text { No } \\
\text { Sampel }\end{array}$ & $\begin{array}{c}\text { Random } \\
\text { Number }\end{array}$ \\
\hline 1 & 118.85051 & 11 & 156.36231 \\
2 & 207.37679 & 12 & 235.81909 \\
3 & 245.29611 & 13 & 136.08751 \\
4 & 77.691600 & 14 & 71.231469 \\
5 & 100.10581 & 15 & 211.23541 \\
6 & 75.803730 & 16 & 62.382109 \\
7 & 86.509960 & 17 & 159.07371 \\
8 & 59.166180 & 18 & 273.42259 \\
9 & 282.83461 & 19 & 21.377161 \\
10 & 114.87989 & 20 & 278.69209 \\
\hline
\end{tabular}

According to above result, mean value and deviation standard are then obtained. Calculation result using real data and MCS are shown in Table 5.

Table 5. Real data and MCS result

\begin{tabular}{ccccc}
\hline Component & Data & Mean & $\begin{array}{c}\text { Std. } \\
\text { Deviation }\end{array}$ & $\begin{array}{c}1 / \mathrm{E}(\mathrm{x})= \\
\lambda\end{array}$ \\
\hline JE01/AP- & TTF & 203.57 & 156.75 & - \\
$01-02$ & Random & 233.62 & 142.74 & - \\
KBE01/AP- & TT F & 166.50 & - & 0.0060 \\
$01-02$ & Random & 148.71 & - & 0.0067 \\
\hline
\end{tabular}

Reliability analysis for components JE01/AP01-02 and KBE01/AP-01-02 using real data and MCS was carried out based on data from Table 5. Component reliability curves of JE01/AP-01-02 for real data are shown in Figure 3 and data The MCS is shown in Figure 4. 


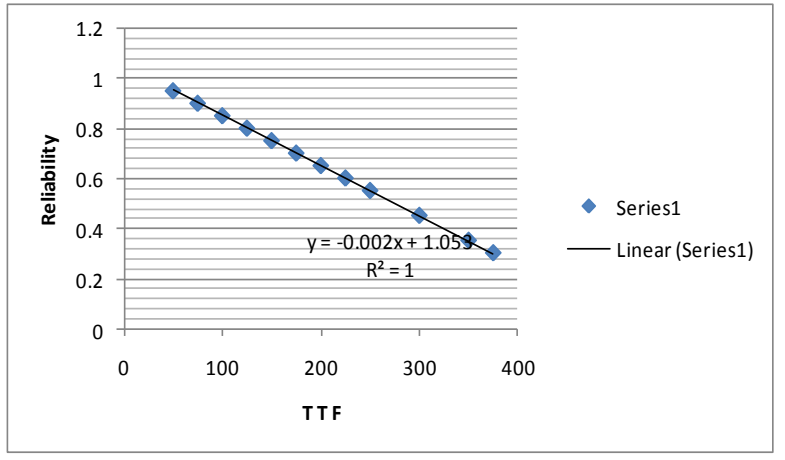

Fig. 3. Reliability of ComponentsJE01 / AP-01-02 from Real Data

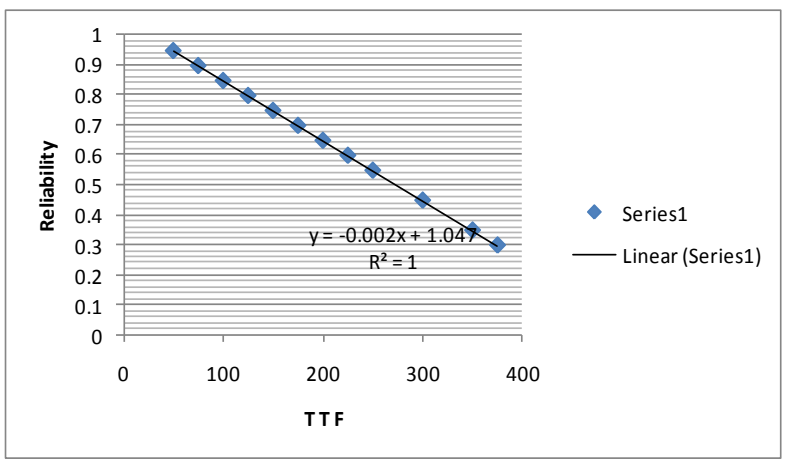

Fig. 4. Reliability of Components JE01/AP-01-02 from MCS data

Based on Figure 3 and Figure 4, a linear equation is obtained to estimate the reliability values of components of JE01/AP-01-02 from real data and MCS. The linear equation of the reliability function for real data is $\mathrm{y}=-0.002 \mathrm{x}+1.053$, while for Monte Carlo simulation data is $\mathrm{y}=-0.002+$ 1.047. From the equations above, we estimate the reliability values for real data and MCS.

Based on the reliability function equation above, the reliability value of components JE01/ AP-01-02 for real data on TTF of 203.571 is 0.63986 and for MCS data on TTF of 233.619 is 0.579762 . The calculation results of the reliability components JE01/AP-01-02 for TTF values 50 to 375 are shown in Table 6.

Table 6. Reliability of ComponentsJE01 / AP-01-02

\begin{tabular}{ccc}
\hline TTF & R (riil) & R(MC) \\
\hline 50 & 0.953 & 0.947 \\
75 & 0.903 & 0.897 \\
100 & 0.853 & 0.847 \\
125 & 0.803 & 0.797 \\
150 & 0.753 & 0.747 \\
175 & 0.703 & 0.697 \\
200 & 0.653 & 0.647 \\
225 & 0.611 & 0.605 \\
250 & 0.553 & 0.527 \\
300 & 0.453 & 0.447 \\
350 & 0.353 & 0.347 \\
375 & 0.303 & 0.297 \\
\hline
\end{tabular}

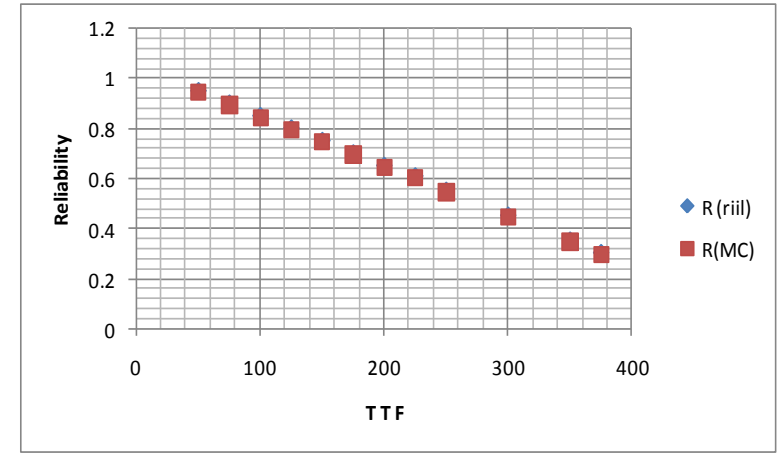

Fig. 5. Reliability of Components JE01 / AP-01-02

From Table 7 and Figure 5 for components JE01/AP-01-02, the value of TTF $=50$, the reliability value based on real data is obtained at 0.953 and for Monte Carlo simulation data is 0.947 . The reliability of the component is around 0.52 or $50 \%$, so the TTF value is 250 . Thus, the maintenance interval can be done every 250 days.

Based on the reliability function equation for exponential distribution, namely $R(t)=\operatorname{Exp}(-\lambda t)$, the estimated value of component reliability for real data on TTF of 166.5 is 0.367 and for MCS data on TTF of 148.71 is 0.368 .The results of the reliability calculation of components KBE01/AP-01-02 for TTF values of 50 to 375 are shown in Table 7 .

Table 7. Reliability of Components of KBE01/AP01-02

\begin{tabular}{ccc}
\hline TTF & $\mathrm{R}(\mathrm{t})$ riill & $\mathrm{R}(\mathrm{MC})$ \\
\hline 50 & 0.740 & 0.715 \\
75 & 0.637 & 0.605 \\
100 & 0.548 & 0.511 \\
125 & 0.472 & 0.432 \\
150 & 0.406 & 0.365 \\
175 & 0.349 & 0.309 \\
200 & 0.301 & 0.261 \\
225 & 0.259 & 0.221 \\
250 & 0.223 & 0.186 \\
275 & 0.192 & 0.158 \\
300 & 0.165 & 0.133 \\
325 & 0.142 & 0.113 \\
350 & 0.122 & 0.095 \\
375 & 0.105 & 0.080 \\
\hline
\end{tabular}




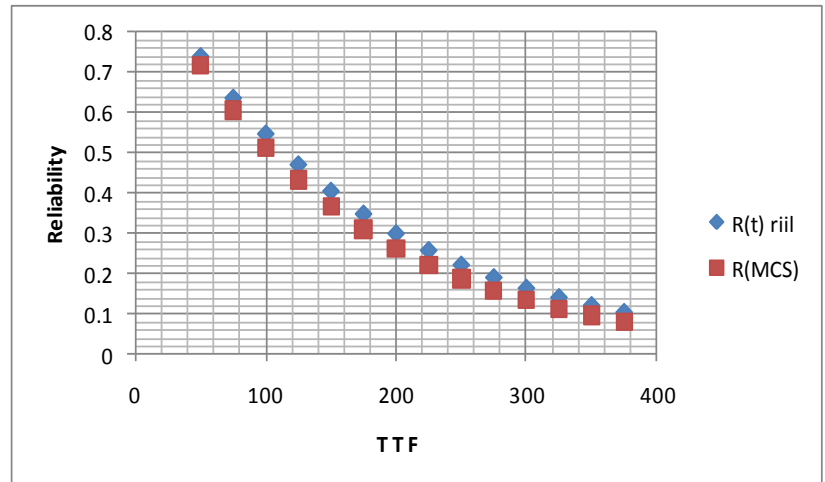

Fig. 6. Reliability of Components KBE01 / AP-01-02

From Table 7 and Figure 6, the reliability value for components KBE01/AP-01-02 may be understood.The value of TTFis 50 , the reliability value based on real data will be obtained at 0.740 and for MCS data is 0.715. Reliability of the component $=0.51$ or around $50 \%$, the TTF value is 100 , so the maintenance interval can be performed every 100 days.

\section{CONCLUSION}

Data limitations in the analysis can affect the output value. Simulation-based Monte Carlo analysis, by considering uncertainty, may be employed to perform component/system reliability analysis and evaluation of maintenance decisions. From the calculation of component reliability based on the maintenance data of core configuration number of 81-95, the results obtained are as follows. The reliability values of components JE01/AP01-02 on TTF 233.619 is 0.579 while for components KBE01/AP-01-02 in TTF 185.38 is 0.368 . The component reliability value is $60 \%$, then the maintenance interval may be performed after 225 days for components JE01/AP01-02 and 100 days for components KBE01/AP01-02.

\section{ACKNOWLEDGMENT}

The author would like to acknowledge Dr. M. Subekti who has supported this research.This research is funded by DIPA PTKRN BATAN 2018.

\section{REFERENCES}

1. Hartini E, Dibyo S, Pujiarta S. Determination of Maintenance Priority Index (MPI) for Components on RSG-Gas Safety System, Tri Dasa Mega. 2018. 22(3):77-88.

2. Deswandri, Subekti M, Sunaryo G.R. Reliability Analysis of RSG-GAS Primary Cooling System to Support Aging Management Program. J. Phys. Conf. Ser. 2018. 962:1-16.

3. Hartini E, Susmikanti M. Reliability
Analysis for Critical omponent on The RSGGas Primary Cooling System. Sigma Epsilon.2018,22 (2): 71-79

4. Susmikanti M, Hartini E, Saepudin A, Sulistyo J.B.Component Analysis of Purification System of RSGGAS.Pengembangan Energi Nuklir. 2018.20.(1): 31-39.

5. Hartini E. Implementation of Missing Values Handling Method for Evaluating the System/Component Maintenance Historical Data.Tri Dasa Mega. 2017.19 (1). : 11-18 .

6. Andriulo S., Arleo M.A., Carlo F. De, Gnoni M.G., Ghonii M.T. Effectiveness of of maintenance approaches for High Reliability Organizations. IFAC-PapersOnLine. 2015. 48(3):466-71.

7. Florian M., Dalsgaard J. Planning of operation\& maintenance using risk and reliability based methods.Energy Procedia ; 2015,80: $357-364$.

8. Vishnu C.R., Regikumar V. Reliability Based Maintenance Strategy Selection in Process Plants: A Case Study. Procedia Technol. 2016. 25:1080-7.

9. Zio, Enrico.The Monte Carlo Simulation Method for System Reliability and Risk Analysis. Reliab. Eng, 2013

10. H. Abdo.J-M Flaus, Monte Carlo simulation to solve fuzzy dynamic fault tree. IFACPapersOnLine. 2016.49(12) :1886-1891

11. Hui Chen, Longbiao Li,Youchao Sun.Risk Assessment of Aero Engine Failure Based on MonteCarlo

Simulation.ProcediaEngineering. 2014. 80. : $415-423$

12. Lorentz Jantschi, Sorana D. B.Computation of Probability Associated with AndersonDarling Statistic. Mathematics. 2018. 6. 88.

13. Nikolovski F, Juričić Đ, Dolenc B. On optimal maintenance strategy using discreteevent Monte Carlo simulation. 2014.:183-6.

14. Joao Silva.Definition of Maintenance Policies in Power Systems Using a Sequential Monte Carlo. J. P. Eng.2015. 1:122-37.

15. Aslett L.J.M. Nagapetyan T., Vollmer S.J. Multilevel Monte Carlo for Reliability Theory. Reliab. Eng. Syst. Saf. 2017. 165:188-96.

16. Sreenuch T., Alghassi A., Perinpanayagam S. Probabilistic Monte-Carlo Method for Modelling and Prediction of Electronics Component Life. Int.J. Advanced Computer Science and Application.2014. 5(1):96-104. 
17. Proppe, C. Markov Chain Monte Carlo Simulation Methods for Structural Reliability Analysis, Procedia engineering. 2017.199, 1122-1127.

18. S. Raissi, Sh. Ebadi. A Computer Simulation Model for Reliability Estimation of a Complex System, Int. J. Res. Ind. Eng. 2018,7 (1) : 19-31

19. M. Jirgl. M. Havlikova. Z. Bradac. L. Stastny.Monte Carlo Reliability Analysis of Systems with a Human Operator.IFACPapersOnLine. $2016.49: 272-277$

20. Center for Multipurpose Reactor. Report on Reactor Operation of RSG-GAS. 2013-2018 